AperTO - Archivio Istituzionale Open Access dell'Università di Torino

\title{
Understanding plant cell-wall remodelling during the symbiotic interaction between Tuber melanosporum and Corylus avellana using a carbohydrate microarray
}

\section{This is the author's manuscript}

Original Citation:

Availability:

This version is available http://hdl.handle.net/2318/1560249

since 2017-05-15T10:57:22Z

Published version:

DOI:10.1007/s00425-016-2507-5

Terms of use:

Open Access

Anyone can freely access the full text of works made available as "Open Access". Works made available under a Creative Commons license can be used according to the terms and conditions of said license. Use of all other works requires consent of the right holder (author or publisher) if not exempted from copyright protection by the applicable law. 


\section{(3) \\ UNIVERSITÀ DEGLI STUDI DI TORINO}

This is an author version of the contribution published on:

Questa è la versione dell'autore dell'opera:

[Planta, 2016, DOI: 10.1007/s00425-016-2507-5]

The definitive version is available at:

La versione definitiva è disponibile alla URL:

[http://link.springer.com/article/10.1007/s00425-016-2507-5/fulltext.html] 
Understanding plant cell-wall remodelling during the symbiotic interaction between Tuber melanosporum and Corylus avellana using a carbohydrate microarray

Fabiano Sillo, Jonatan U. Fangel, Bernard Henrissat, Antonella Faccio, Paola Bonfante, Francis Martin, William G. T. Willats, Raffaella Balestrini

Keywords: Carbohydrate-Active enZYmes, CoMPP, Ectomycorrhiza, Hazel, Plant cell wall, Tuber

Abbreviations

CBM: Carbohydrate-binding module

COMPP: Comprehensive microarray polymer profiling

GH: Glycoside hydrolase

HG: Homogalacturonan

PCWDEs: Plant cell-wall degrading enzymes 


\section{Introduction}

Plant cell walls consist of a number of distinct biopolymers that are woven together into a complex network. They are the key determinants of plant shape, growth and development, and are collectively the largest source of biomass on earth. Although differing in macromolecular composition, plant cell walls are responsible for many of the same functions as animal extracellular matrixes, connecting cells into tissues, and they are involved in signalling cell growth and division (Lodish et al. 2000). Cell walls also constitute a plant's first line of defence against pathogens, and are an important feature that should be considered concerning the changes in cell wall composition during interactions with other organisms. However, plant cell walls are not only a substrate for the growth of fungi and a barrier to infection from parasites, they are also the first surface where contact with symbiotic fungi occurs (Balestrini and Bonfante 2014). In ectomycorrhizae, plant and fungal cell walls come into direct contact, and they represent the interface between the two partners. When the fungal hyphae penetrate the plant root cells, only subtle alterations can be observed in the plant cell walls, although a localized loosening has been reported in several ectomycorrhizal systems (Balestrini et al. 1996; Balestrini and Bonfante 2014).

It has recently been reported that the genomes of the ectomycorrhizal fungi Laccaria bicolor and Tuber melanosporum contain a reduced gene set involved in the production of enzymes that are active on plant cell-wall polysaccharides (Martin et al. 2008, 2010), in comparison with saprotrophic and pathogenic fungi (Martin and Selosse 2008). A reduced set of plant cell-wall degrading enzymes (PCWDEs) has also been reported for Amanita bisporigena by Nagendran et al. (2009), who showed that this ectomycorrhizal fungus lacks the genomic potential to biosynthesize many extracellular enzymes that are active on the linkages in the plant cell wall and, in particular, exhibits a loss of several key cellulase genes. A large-scale comparative genomics analysis of fungal genomes with different life-styles, including a dozen ectomycorrhizal fungi, has confirmed that the latter have a reduced complement of genes encoding PCWDEs, thus suggesting that, during their evolution, ectomycorrhizal fungi have lost much of the enzymatic apparatus of their ancestral wood decayers (Kohler et al. 2015). However, several species have retained a restricted set of PCWDEs, which seems to suggest that they still possess some PCW degradation and/or loosening ability (Kohler et al. 2015). In the past, enzymatic activities related to PCWDEs were demonstrated for ectomycorrhizal fungi, and several capacities in different fungal species were reported (Maijala et al. 1991; Cao and Crawford 1993; Colpaert and van Laere 1996; Kusuda et al. 2008). The L. bicolor genome contains a limited repertoire of enzymes putatively active on cellulose and hemicellulose, and it has recently been shown that they are expressed during the first steps of root cell colonization. On the other hand, the L. bicolor enzymes likely involved in pectin hydrolysis are mainly expressed at the fully mature ectomycorrhizal stage (VeneaultFourrey et al. 2014). While the abovementioned studies have focused on the role of PCWDEs in ectomycorrhizae, the effect on plant cell walls during ectomycorrhizal fungal colonization still remains poorly studied and requires further efforts (Balestrini and Bonfante 2014 and references therein).

Although plant and fungal cell-wall components have been previously localized in ectomycorrhizal symbiosis (Balestrini et al. 1996), mapping the complex and diverse glycans in plant cell walls is a considerable technical challenge, mainly in a complex system such as an ectomycorrhiza where plant and fungal tissues are present. Several conventional biochemical techniques are available, but carbohydrate microarrays have emerged as a useful tool for high throughput semi-quantitative analysis. One technique, known as Comprehensive Microarray Polymer Profiling (CoMPP), has been used extensively to map defined glycan structures (epitopes) across large sample sets (Moller et al. 2007; Sørensen and Willats 2011). CoMPP involves the sequential extraction of cell wall polymers, which are printed as microarrays and probed with sets of cell wall-specific monoclonal antibodies (mAbs) and carbohydrate-binding modules 
(CBMs) (Moller et al. 2007, 2008). CoMPP combines the high throughput capacity of microarray technology with the specificity of $\mathrm{mAbs}$ and $\mathrm{CBMs}$, and allows glycan profiles to be rapidly generated in diverse systems. It has been used to study polysaccharide diversity across the plant kingdom (Fangel et al. 2012), and in different conditions, such as during interactions with other living organisms (Moller et al. 2011; Hansen et al. 2014; Johnsen et al. 2015). Recently, this approach has been applied in an elegant study aimed at understanding the interaction between the plant parasite Cuscuta reflexa and its host plant, starting from the idea that the compositional differences of cell walls could explain why some hosts are amenable to such degradation while others can resist infection (Johnsen et al. 2015).

Taking advantage of CoMPP technology, the current study is aimed at establishing the changes in plant cell wall composition in common hazel (Corylus avellana) roots during colonization by the ascomycetous ectomycorrhizal fungus T. melanosporum. This specific plant-fungus interaction has here been focused on as the hazelnut tree is a typical host plant for truffles, and in fact, it has also been used to analyse the T. melanosporum transcriptome during the symbiotic stage (Martin et al. 2010; Tisserant et al. 2011). Genes encoding putative PCWDEs were identified in the T. melanosporum genome, and previous large-scale transcriptomics data (Martin et al. 2010) of candidate genes were validated, using RT-qPCR, on C. avellana/T. melanosporum ectomycorrhizae.

\section{Materials and methods}

\section{Biological materials}

Fully developed Tuber melanosporum ectomycorrhizae and non-mycorrhizal root tips from the root systems of 1 year and a half old hazel plantlets (Corylus avellana L.), previously inoculated by a T. melanosporum mycelium slurry produced from a fruiting body (Martin et al. 2010), and grown in the AGRITRUFFE greenhouse facilities (Saint-Maixant, France) have been sampled under a stereomicroscope. A section of one ectomycorrhiza representative of those used in this work is shown in Supplementary Fig. S1, where it is possible to appreciate the presence of a considerable amount of fungal tissue. On the basis of the RNA proportion, it has been estimated that the amount of Tuber mycelium in ectomycorrhizal roots at this development stage is $\sim 30 \%$ (Tisserant et al. 2011). The T. melanosporum mycelium (Tmel28 strain) used for the molecular analysis was grown in a liquid modified Melin Norkrams (MMN) medium in a dark room at $25^{\circ} \mathrm{C}$ for 1 month before harvesting.

\section{Detection of putative PCWDEs encoded by Tuber melanosporum}

The gene models (putative genes) corresponding to the proteins involved in plant cell-wall synthesis/degradation were identified at the TuberDB Tuber genome v. 1 database (http://mycor.nancy.inra.fr/IMGC/TuberGenome/). The best protein models from Tubme1 were compared with the sequences in the Carbohydrate Active Enzymes database (CAZy; www.cazy.org) (Lombard et al. 2014), and the proteins that generated a better e value than 0.1 were considered for a manual analysis. The latter step involved comparisons with the individual protein domains constitutive of CAZymes to eliminate false positives and assign the remaining proteins to the appropriate family (or families in the case of multiple CAZy modules). The sequences assigned to the glycosyl hydrolase (GH) GH5 and GH13 families 
were further assigned to subfamilies, as described in Aspeborg et al. (2012) and Stam et al. (2006), respectively. Signal peptides were predicted using Phobius (Käll et al. 2004).

\section{Functional annotation of putative PCWDEs}

To carry out a functional prediction of the putative PCWDEs, a sequence library was built with only the sequences corresponding to CAZymes with published activity, as listed on the characterized pages of the CAZy database (for instance http://www.cazy.org/GH5_characterized.html for the GH5 family). This sequence library, which counts over 12,000 sequences, was interrogated with BLAST using the putative PCWDE sequences as queries. In other words, the aminoacid sequences of all the encoded GHs, polysaccharide lyases (PLs), carbohydrate esterases (CEs) and auxiliary activities (AAs) were used as queries against all the sequences of the experimentally characterized CAZymes derived from the CAZy database. Significant hits (with a better e value than 10-6) with experimentally characterized PCWDEs were considered to be putative PCWDEs and retained for activity prediction. Activities were only considered predicted when the hits displayed at least $40 \%$ sequence identity with the aminoacid sequence of a characterized PCWDE, to avoid problems due to the presence of multiple specificities in a given CAZy family.

\section{RNA isolation and CDNA synthesis}

Total RNA extraction from the mycelium and ectomycorrhizae was carried out using the 'pine tree method' (Chang et al. 1993). Genomic DNA was removed using a Turbo DNA-free ${ }^{\mathrm{TM}}$ reagent (Ambion, Austin, TX, USA), according to the manufacturer's instructions. The cDNA synthesis has been described in detail in Balestrini et al. (2012).

\section{Gene expression analysis}

Large-scale transcriptomic data were previously obtained from a T. melanosporum custom-exon expression array $(4 \times 72 \mathrm{~K})$ manufactured by Roche Nimblegen Systems Limited (Madison, WI, USA) and from massive cDNA sequencing, with Illumina technology, of the samples of the free living mycelium and ectomycorrhizae, as described in detail in Martin et al. (2010). Quantitative RT-PCR (RT-qPCR) experiments were conducted to validate the large-scale transcriptomic results. Specific primers were designed for the considered genes (Table S1) using PerlPrimer software v 1.1.19 (http://perlprimer.sourceforge.net/) and verified by means of Primer BLAST Software (http://www.ncbi.nlm.nih.gov/tools/primer-last/index.cgi). Before RT-qPCR, the primers were tested on genomic DNA from T. melanosporum mycelium (as a positive control) and C. avellana leaves (as a negative control). Genomic DNA was extracted using a DNeasy Plant Mini Kit (QIAGEN, Valencia, CA, USA). To assess the specificity of the primers, RT-PCR on CDNA from T. melanosporum mycelium was performed as described in Sillo et al. (2015) and amplified products were sequenced. Purification of products was performed using ExoSAP-IT (Affymetrix, Santa Clara, CA, USA) at 37 ${ }^{\circ} \mathrm{C}$ for $15 \mathrm{~min}$ and subsequently at $80^{\circ} \mathrm{C}$ for $15 \mathrm{~min}$. The purified products were sequenced at BMR Genomics S.R.L. (Padua, Italy). Each sequence was aligned with the coding sequence of its gene model using MEGA v. 6.0 (Tamura et al. 2013). 
Quantitative RT-PCR was carried out with StepOne apparatus (Applied Biosystems, Foster City, CA, USA). Each PCR was performed in a volume of $20 \mu$ l containing $10 \mathrm{ng}$ CDNA $(1 \mu \mathrm{l}), 10 \mu \mathrm{l} 2 \times$ SYBR $^{\circledR}$ Green PCR Master Mix (Applied Biosystems) and $2 \mu$ lof each primer ( $3 \mu \mathrm{M}$ stock) using a 48-well plate. The following PCR programme, which includes the calculation of a melting curve, was used: $95^{\circ} \mathrm{C}$ for $10 \mathrm{~min}, 45 \mathrm{cycles}$ of $95{ }^{\circ} \mathrm{C}$ for $15 \mathrm{~s}, 60^{\circ} \mathrm{C}$ for $1 \mathrm{~min}, 95^{\circ} \mathrm{C}$ for $15 \mathrm{~s}, 60$ for $1 \mathrm{~min}, 95^{\circ} \mathrm{C}$ for $15 \mathrm{~s}$. The baseline range and $\mathrm{CT}$ values were automatically calculated using the StepOne software. The expression of candidate genes was normalized to that of TmelEF1B (Sillo et al. 2013), which was used as the housekeeping gene, by subtracting the $\mathrm{CT}$ value of TmelEF1B from the CT value of the candidate gene resulting from the $\triangle \mathrm{CT}$. The expression ratio was calculated, without the PCR efficiency correction, from Eq. $2-\Delta \Delta C T$, where $\Delta \Delta C T$ represents the $\Delta C T$ sample $-\triangle C T$ control. All the reactions were performed for two biological and three technical replicates. Statistical analyses were carried out using Rest2008, version 2.0.7 (Pfaffl et al. 2002), considering data with a $P$ value $<0.05$ as being significantly different.

\section{Cell wall material preparation}

The cell wall material for the CoMPP analysis was prepared from ectomycorrhizae and non-mycorrhizal root tips as an alcohol-insoluble residue (AIR). Samples were collected carefully from the hazelnut root system using a sterile scalpel and tweezers, and placed in 2-ml tubes. The collected samples were dry-lyophilized overnight and homogenized into powder using Tissue Lyser $(5 \mathrm{~min}, 28 \mathrm{~Hz}$ ). Subsequently, the samples were re-suspended in $70 \%$ ethanol for $30 \mathrm{~min}$ at room temperature under rotation. The supernatant was removed after centrifugation at 22,000 g for $10 \mathrm{~min}$. This step was performed five times. The time of suspension in $70 \%$ ethanol was increased to $60 \mathrm{~min}$ for the last two steps. A final wash was performed with $100 \%$ acetone, and an AIR pellet was recovered after a final centrifuge at 22,000g for $15 \mathrm{~min}$. The AIR pellet was dried at room temperature.

\section{Comprehensive microarray polymer profiling}

CoMPP was carried out as described in Moller et al. (2007). Cell wall polymers were extracted sequentially from $10 \mathrm{mg}$ of AIR with $300 \mu \mathrm{l}$ of $50 \mathrm{mM}$ diamino-cyclo-hexane-tetra-acetic acid (CDTA), pH 7.5 and $4 \mathrm{M}$ $\mathrm{NaOH}$ with $0.1 \% \mathrm{v} / \mathrm{v} \mathrm{NaBH} 4$ and spotted on a nitrocellulose membrane with a pore size of $0.45 \mu \mathrm{m}$ (Whatman, Maidstone, UK) using an Arrayjet Sprint (Arrayjey, Roslin, UK). Each sample was printed with two technical replicates and four dilutions, and probed as described in Pedersen et al. (2012). The arrays were scanned using a flatbed scanner (CanoScan 8800 F, Canon, Søborg, Denmark) at $2400 \mathrm{dpi}$ and quantified using Array-Pro Analyzer 6.3 (Media Cybernetics, Rockville, MD, USA). The error bars represent the SE values of six independent extractions.

\section{Immunogold labelling}

Immunogold experiments were performed as described in Balestrini et al. (1996). Monoclonal antibodies (mAbs) JIM5 and JIM7 (Knox et al. 1990; Verhertbruggen et al. 2009; Carbon Source, Athens, GA, USA) were used (1:10 dilution) to localize homogalacturonan (HG) with a different esterification degree (JIM5 recognizes partially methyl-esterified HG epitopes, including un-esterified HG; JIM7 recognizes more methyl-esterified HG epitopes, and does not bind to un-esterified HG), while an mAb anti- $\beta$-1,3-glucan 
(Biosupplies, Parkville, Australia) was used to localize glucans (1:100 dilution). The primary antibody was omitted for the negative control. Thin sections $(0.05-0.07 \mu \mathrm{m})$ were post-stained with uranyl acetate and lead citrate before being observed under a Philips CM10 transmission electron microscope (Philips, Eindhoven, The Netherlands).

\section{Results}

\section{Catalogue of genes coding PCWDEs in T. melanosporum}

The several GHs, PLs and CEs have been identified in the T. melanosporum genome. The manual annotation and activity prediction of genes coding PCWDEs are reported in Table 1. Genes coding for cellulolytic enzymes such as the proteins of the GH5_5, GH12, GH45 (endoglucanases) and AA9 (lytic polysaccharide mono-oxygenases that oxidatively cleave cellulose) families have been found, while the cellobiohydrolases of the GH6 and GH7 families were absent from the T. melanosporum genome. Pectin degradation enzymes are represented by members of the PL1 (pectin/pectate lyases), PL4 (rhamnogalacturonan lyase), CE12 (rhamnogalacturonan acetylesterase), GH28 (polygalacturonases), GH43 ( $\alpha$-L-arabinanase), GH78 ( $\alpha$-Lrhamnosidases) and CE8 (pectin methylesterase) CaZy families. Only one putative xylanase (GH10 family) appears to be encoded by the T. melanosporum genome. Most of the PCWDEs appear to have a secretion signal peptide (Table 1), and a lytic polysaccharide monooxygenase (LPMO) of the AA9 family (JGI ID = 3661) carries a cellulose-binding domain (CBM1) module.

\begin{tabular}{|c|c|c|c|c|c|c|}
\hline Substrate & Gene model\# & Gene name & $\begin{array}{l}\text { CAZy } \\
\text { family }\end{array}$ & Predicted activity & Signal peptide & $\begin{array}{l}\text { JGil protein } \\
\text { ID }\end{array}$ \\
\hline \multicolumn{7}{|l|}{ Cellulose } \\
\hline & GSTUMT00008973001 & TmelCMC3 & GH5_5 & Endoglucanase & No & 5467 \\
\hline & GSTUMT00008986001 & TmelLPMOI^ & AA9 & LPMO* & Yes & 5474 \\
\hline & GSTUMT00001211001 & TmelLPMO2 & AA9 & LPMO* & $\begin{array}{l}\text { No (fragment too short at } \\
\text { N-term) }\end{array}$ & 3661 \\
\hline & GSTUMT00009298001 & Tmelcel & $\mathrm{GH} 12$ & Endoglucanase & Yes & 5666 \\
\hline & GSTUMTO0011089001 & TMelEG & GH45 & Endoglucanase & Yes & 6760 \\
\hline \multicolumn{7}{|l|}{ Pectin } \\
\hline & GSTUMTro0008534001 & TMeIPLB & PL.1 & Pectin/pectate lyase & Yes & 5163 \\
\hline & GSTUMTO0006239001 & Tmelpnla & PLI & Pectin/pectate lyase & $\begin{array}{l}\text { No (fragment too short at } \\
\text { N-term) }{ }^{* *}\end{array}$ & 3478 \\
\hline & GSTUMTO0004952001 & TmelrghB & PLA & Rhamnogalacturonan lyase & Yes & 1834 \\
\hline & GSTUMTO0003723001 & $T m e l R_{g} a E$ & CE12 & $\begin{array}{l}\text { Rhamnogalacturonan } \\
\text { acerylesterase }\end{array}$ & Yes & 2410 \\
\hline & GSTUMTO0012011001 & TmelPGNI & $\mathrm{GH} 28$ & Polygalacturonase & Yes & 7339 \\
\hline & GSTUMTO0004199001 & TmelrghA & GH28 & Polygalacturonase & Yes & 268 \\
\hline & GSTUMT00012789001 & Tmelpmel & CE8 & Pectin medhylesterase & Yes & - \\
\hline & GSTUMTO0003229001 & TmelabnA & GH43 & $\alpha$-L-arabinanase & Yes & 1920 \\
\hline & GSTUMT00005050001 & Tmelrhal & $\mathrm{GH} 78$ & $\alpha$-L-rhamnosidase & Yes & 2086 \\
\hline & GSTUMT00006913001 & Tmelrha2 & GH78 & $\alpha$-L-thamnosidase & № & 4095 \\
\hline \multicolumn{7}{|c|}{ Hemicellulose } \\
\hline & GSTUMTO0009198001 & TmelxinA & GH10 & xylanase & No & 5607 \\
\hline
\end{tabular}

Validation of large-scale transcriptome data

The expression of PCWDEs in T. melanosporum was carried out for three growth conditions (ectomycorrhizal root tips; fruiting bodies and free-living mycelium) using RNA-Seq and cDNA arrays, as described in Martin et al. (2010). These analyses have shown that several of these genes are regulated 
during the symbiotic stage (Martin et al. 2010; Table 2). The complete expression data set is available as a series (accession number GSE17529) in the Gene Expression Omnibus at NCBI

(http://www.ncbi.nlm.nih.gov/geo/). According to the cDNA array results, 8 out of 16 genes encoding putative PCWDEs were more than 4-fold up-regulated in the T. melanosporum ectomycorrhiza vs. the freeliving mycelium (FLM) (Table 2). Here, nine gene models coding for enzymes putatively acting on cellulose (i.e., TmelCMC3, TmelLPMO1, Tmelcel, TmelEG) and on pectin (i.e., TmelPLB, TmelRgaE, TmelPGN, TmelrghA, Tmelpme1) were considered in quantitative RT-PCR (RT-qPCR) reactions to evaluate their expression in fully established ectomycorrhizae compared to free-living mycelium. As reported in Table 2, the results confirmed the array trend for almost all of the considered genes, although with some differences. In other words, RT-qPCR experiments showed a high up-regulation of a gene coding for a putative rhamnogalacturonan acetylesterase (TmelRgaE) that appeared only slightly regulated in the array (although with a non-significant $P$ value $>0.05$ ), and a gene coding for an AA9 (TmelLMPO1), which was only weakly up-regulated in the array, also resulted to be highly up-regulated. Unlike for the array data, a gene coding for a putative pectin/pectate lyase (TmelPLB) also resulted to be up-regulated, in agreement with the RNAseq data. 
Table 2 Expression values in RT-qPCR ( \pm SD), microarray and RNAseq analyses

\begin{tabular}{|c|c|c|c|c|c|c|c|c|c|}
\hline Gene name & Blastp (best identified match) & Organism & $\begin{array}{l}\text { Query } \\
\text { coverage }(\%)\end{array}$ & $e$ value & $\begin{array}{l}\text { Identity } \\
(\%)\end{array}$ & $\begin{array}{l}\text { Fold change RT- } \\
\text { qPCR }\end{array}$ & $\begin{array}{l}\text { Array ratio } \\
\text { ECM/FLM }\end{array}$ & $\begin{array}{l}\text { RNAseq ECM } \\
\text { (RPKM) }\end{array}$ & $\begin{array}{l}\text { RNAseq FLM } \\
\text { (RPKM) }\end{array}$ \\
\hline TmelCMC3 & $\begin{array}{l}\text { Similar to Probable endo-beta-1,4 } \\
\text { glucanase B }\end{array}$ & $\begin{array}{l}\text { Pyronema } \\
\text { omphalodes }\end{array}$ & 92 & $1 \mathrm{e}-171$ & 75 & $143.83 \pm 16.97$ & 6212.62 & 245.2 & 0.0 \\
\hline Tmelcel & $\begin{array}{l}\text { Similar to Xyloglucan-specific endo- } \\
\text { beta-1,4 glucanase A }\end{array}$ & $\begin{array}{l}\text { Pyronema } \\
\text { omphalodes }\end{array}$ & 99 & $8 e-87$ & 57 & $199.62 \pm 11.47$ & 225.22 & 71.5 & 1.8 \\
\hline TmelEG & Endoglucanase-5 & $\begin{array}{l}\text { Pyrenophora tritici- } \\
\text { repentis }\end{array}$ & 100 & $4 e-100$ & 62 & $14.34 \pm 15.38$ & 14.65 & 24.0 & 2.3 \\
\hline TmelRgaE & $\begin{array}{l}\text { Similar to Rhamnogalacturonan } \\
\text { acetylesterase }\end{array}$ & $\begin{array}{l}\text { Pyronema } \\
\text { omphalodes }\end{array}$ & 87 & $1 \mathrm{e}-142$ & 66 & $224.72 \pm 12.06$ & $4.44^{*}$ & 83.4 & 6.4 \\
\hline TmelPGNI & Putative endopolygalacturonase & Diplodia seriata & 97 & $4 e-146$ & 62 & $22.91 \pm 24.83$ & 29.46 & 244.2 & 16.4 \\
\hline TmelrghA & Putative endo-rhamnogalacturonase $f$ & $\begin{array}{l}\text { Phaeomoniella } \\
\text { chlamydospora }\end{array}$ & 79 & $2 \mathrm{e}-154$ & 58 & $4.72 \pm 11.00^{*}$ & 4.63 & 18.9 & 4.0 \\
\hline Tmelpmel & Carbohydrate esterase family 8 protein & $\begin{array}{l}\text { Fomitiporia } \\
\text { mediterranea }\end{array}$ & 64 & $7 e-72$ & 41 & $4.00 \pm 1.10$ & 31.87 & 37.7 & 4.1 \\
\hline TmelabnA & $\begin{array}{l}\text { Arabinan endo-1,5-alpha-L- } \\
\text { arabinosidase A }\end{array}$ & Pestalotiopsis fici & 99 & $3 e-137$ & 64 & - & $1.82^{*}$ & 17.5 & 16.3 \\
\hline Tmelrhal & Alpha-l-rhamnosidase a & $\begin{array}{l}\text { Colletotrichum } \\
\text { orbiculare }\end{array}$ & 93 & 0.0 & 44 & - & $0.86^{*}$ & 20.4 & 11.8 \\
\hline Tmelrha2 & Alpha-L-rhamnosidase & $\begin{array}{l}\text { Streptomyces } \\
\text { xylophagus }\end{array}$ & 91 & 0.0 & 54 & - & $1.12^{*}$ & 3.0 & 1.5 \\
\hline TmelxlnA & Glycoside hydrolase family 10 protein & $\begin{array}{l}\text { Hydnomerulius } \\
\text { pinastri }\end{array}$ & 99 & $3 e-131$ & 61 & - & $0.08^{*}$ & 10.4 & 23.3 \\
\hline
\end{tabular}

Microarray ratio and RPKM values were obtained from Martin et al. (2010). Genes that are not significantly differentially regulated are marked with the asterisk $(P$ value $>0.05)$ $E C M$ Ectomycornhizae, FLM Free-living mycelium, - not analyzed in RT-qPCR, $R P K M$ reads per kb per million mapped reads 
Cell-wall polysaccharides were sequentially extracted from non-mycorrhizal roots and ectomycorrhizae using CDTA and $\mathrm{NaOH}$ solvents. The two bar diagrams that can be observed in Fig. 1 show the mean CoMPP signals obtained for each mAbs. Combining these data across the two extractions, an overview of the changes was obtained in the cell-wall epitope levels in ectomycorrhizae, in comparison with non-colonized hazel roots. Considering non-colonized roots, the CDTA extraction, which mainly solubilises pectins, shows signals for HG, as revealed by the MAbs JIM5, JIM7, LM18, LM19, and LM20, and arabinogalactan proteins (JIM13), while the main epitopes detected in the $\mathrm{NaOH}$ extract are from hemicellulosic mannans (BS-400-4 and LM21), xyloglucans (LM15 and LM25) and xylans (LM10, LM11 and LM23). In the CDTA extract from ectomycorrhizae, the HG content is reduced to a great extent, as shown by the JIM5, JIM7, LM18, LM19, and LM20 signals. In the $\mathrm{NaOH}$ extract, xyloglucans (LM15) and xylans (LM10, LM11, and LM23) are clearly decreased, while the remaining polysaccharides show reductions of smaller magnitude (Fig. 1). In general, the analysis shows that the fungal colonization affects most of the polymer groups. However, due to the presence of cell wall material of fungal origin in the ectomycorrhizal samples (Fig. S1), the observed reduction in all the cell wall polysaccharide groups could also result from a dilution of plant material.

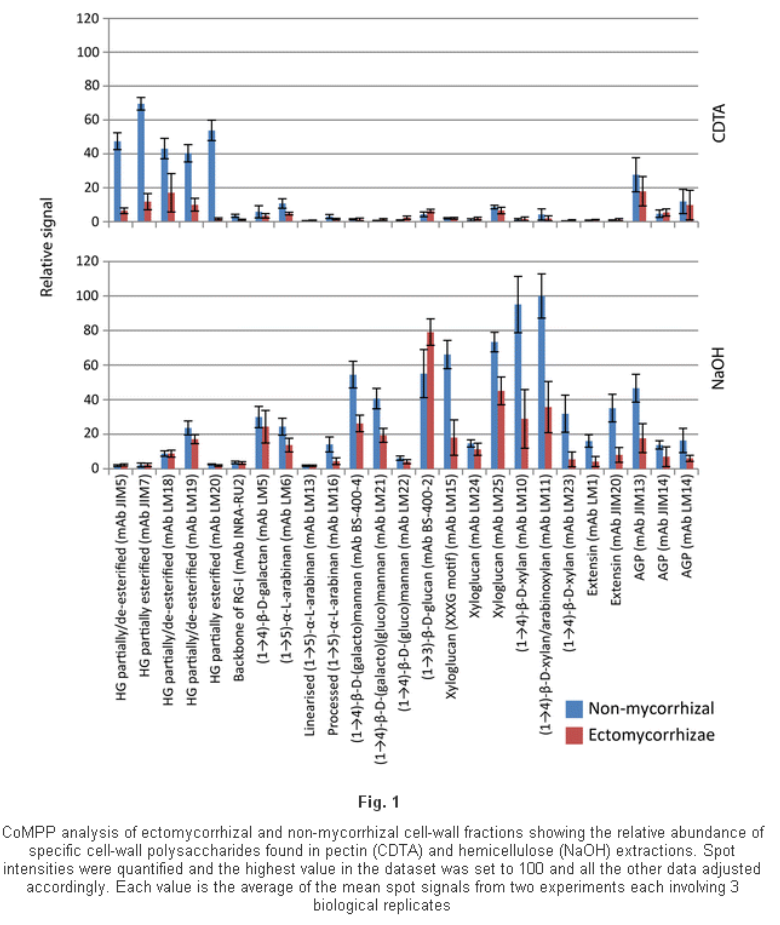

Localization of homogalacturonan in C. avellana/T. melanosporum ectomycorrhizae

Labelling experiments have been performed to localize different methyl-esterified HG on sections of C. avellana ectomycorrhizae and non-colonized roots. When JIM5, which recognizes partially methyl-esterified HG epitopes including un-esterified HG, was used on non-colonized root sections, abundant gold granules appeared on the outer surface of the epidermal cells, on junctions between cells, and on the middle lamella (not shown), in agreement with previous observations (Balestrini et al. 1996). In ectomycorrhizae, fungal hyphae develop among the cortical root cells to form the Hartig net region (Fig. 2a). After treatment with JIM5, gold granules were present on the cell wall surrounding the fungal hyphae in close contact with the fungal cell walls (Fig. 2b, c), as well as in the regions without the fungus, on the middle lamella and on the 
junctions between three host cells (Fig. 2d), as in the non-colonized roots (not shown). The presence of some gold granules in the mantle region is due to collapsed epidermal cells being entrapped among the mantle hyphae, whose external cell walls were labelled, after treatment with JIM5, on non-colonized root sections (not shown). However, only a few gold granules were evident on the plant cell walls (regardless of the cell-type) when mAb JIM7, which recognizes more methyl-esterified HG epitopes, was used, both in the ectomycorrhiza (Fig. 2e) and non-colonized roots (not shown).

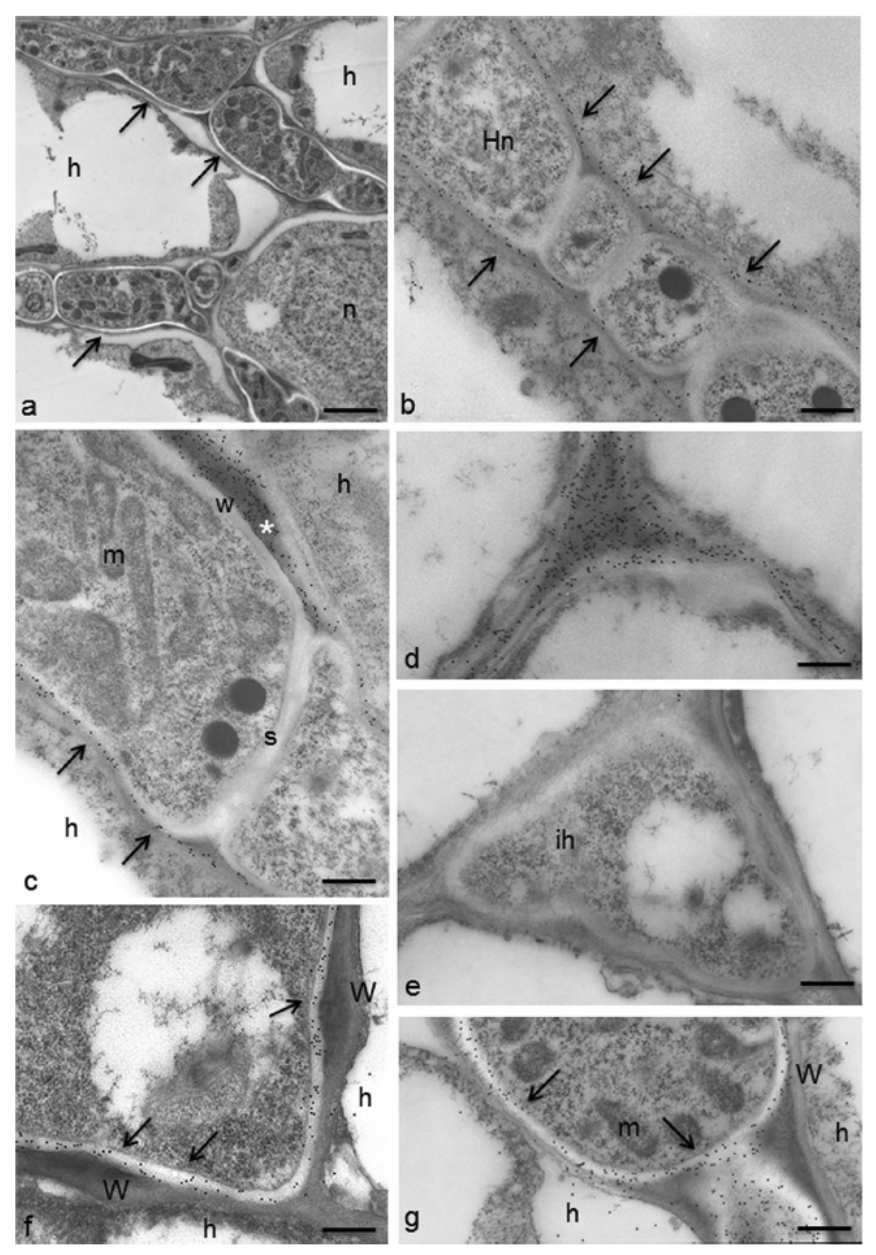

Fig. 2 JIM5 (a-d), JIM7 (e) labelling to localize homogalacturonans and anti- $\beta$-1,3-glucan ( $f, g$ ) labelling on ultra-thin sections of $\mathrm{C}$. avellana/T. melanosporum ectomycorrhiza. a Ultrastructure view of the Hartig net region (arrows). A full set of intracellular organelles is visible within the fungal hyphae. b After treatment with JIM5, homogalacturonan labelling (arrows) is present on the cell wall of the cortical cells bordering the Hartig net $(\mathrm{Hn}$ ) hyphae, while the fungal walls and the electron-dense triangle are not labelled. c Higher magnification of the plant-fungus contact zone in the Hartig net region. Gold granules are present only on the host cell walls (arrows), and consistent labelling is visible on the middle lamella residues (asterisk) attached to the fungal cell wall. $d$ JIM5 labelling of homogalacturonans on noncolonized root cell walls. Evident labelling is present at a junction between cortical cells. e After treatment with antihomogalacturonan JIM7 antibodies on ultra-thin sections of an ectomycorrhiza, only a very few gold granules are present on the plant cell walls bordering an intercellular hypha (ih). $\mathrm{f}, \mathrm{g}$ Localization of $\beta$-1,3-glucans in $\mathrm{C}$. avellana/T. melanosporum ectomycorrhiza. Abundant labelling (arrows) is present on the cell walls of hyphae penetrating the host cells ( $f$ ) and in the Hartig net region ( $g$ ). $h$ host cell, Hn Hartig net, $m$ mitochondria, $n$ nucleus, s septum, w fungal 
cell wall, W plant cell wall. Scale bars $1.5 \mu \mathrm{m}$ (a), $0.56 \mu \mathrm{m}$ (b), $0.47 \mu \mathrm{m}$ (c), $0.43 \mu \mathrm{m}$ (d), $0.39 \mu \mathrm{m}$ (e), $0.36 \mu \mathrm{m}$ (f), 0.48 $\mu \mathrm{m}(\mathrm{g})$

\section{Discussion}

\section{Plant cell wall degrading enzymes in T. melanosporum}

CAZyme (Carbohydrate Active enZymes) annotation has been performed in the frame of T. melanosporum genome project (Martin et al. 2010) and the putative plant cell wall degrading enzymes (PCWDEs) have been identified. Since the last CAZyme annotation of T. melanosporum dates back to the genome sequencing project (Martin et al. 2010), an update of the annotation was performed to take into account the increased number of reference sequences and their improved annotations in the CAZy database (Lombard et al. 2013). The results have confirmed the presence of a reduced set of genes coding PCWDEs, as previously reported (Martin et al. 2010). This is a common feature of all ectomycorrhizal fungi (VeneaultFourrey et al. 2014; Kohler et al. 2015) as well as of brown-rot fungi and the biotrophic fungus Melampsora larici-populina (Duplessis et al. 2011). Enzymes targeting all of the three components of plant cell wall polysaccharides (cellulose, pectin, hemicellulose) have been identified in the T. melanosporum genome, because of their close relationship with biochemically characterized CAZymes. Cellulolytic activities were represented by proteins of the GH5_5, GH12, GH45 (endoglucanases) and AA9 (lytic polysaccharide monooxygenases that oxidatively cleave cellulose) families. It should be noted that the cellobiohydrolases of the GH6 and GH7 families, which intervene in the extensive saccharification of cellulose, were absent from the T. melanosporum genome. In agreement with the known complexity of the substrate (Willats et al. 2006), pectin degradation enzymes were the most numerous in the T. melanosporum genome, with the members of the PL1 (pectin/pectate lyases), PL4 (rhamnogalacturonan lyase), CE12 (rhamnogalacturonan acetylesterase), GH28 (polygalacturonases), GH43 ( $\alpha$-L-arabinanase), GH78 ( $\alpha$-L-rhamnosidases) and CE8 (pectin methylesterase) CAZy families. On the other hand, only one putative xylanase (GH10 family) appears to be encoded by the genome.

Fungal PCWDEs often show a modular structure with CBM1 family non-catalytic modules that target the enzyme appended to cellulose (Levasseur et al. 2013). Although saprotrophic fungi usually have several CBM1-containing proteins (sometimes several dozen), the ectomycorrhizal fungus L. bicolor contains a single CBM1, appended to a GH5 endoglucanase (Martin et al. 2008), and the T. melanosporum genome appears to encode only three proteins that carry a CBM1 module: an LPMO of the AA9 family (JGI ID = 3661; TmelLPMO2), a protein related to tyrosinase (JGI ID = 5167) and a protein of an unknown function (JGI ID = 3974). This result is also in agreement with the recent data which show that proteins with a cellulose-binding domain (CBM1) are rarely detected in ectomycorrhizal fungal genomes, while they are abundant in the orchid and ericoid mycorrhizal fungal symbionts (Kohler et al. 2015).

\section{Expression of T. melanosporum PCWDEs during symbiosis}

Less information is available on the colonization mechanisms of symbiotic fungi than on the hydrolytic activities of plant pathogenic microbes and fungi (Kubicek et al. 2014). Recently, genome-wide transcriptome profiling, during ectomycorrhiza development, has been used to explore the L. bicolor 
CAZome (i.e., the collection of carbohydrate-active enzymes encoded by the genome of an organism) during symbiosis establishment (Veneault-Fourrey et al. 2014). Here, RT-qPCRs were performed to validate the array data that originated in the frame of the T. melanosporum genome project (Martin et al. 2010), and the results confirmed the array trend of almost all of the considered genes (Table 2). As already reported in Balestrini et al. (2012), differences in gene expression data obtained using different techniques are generally present when the array data are not significant (with a P value $>0.05$ ), but they can also be explained considering the variability in the biological material sampling methods. Fully developed ectomycorrhizae are collected from plants grown in pots, but they might not be at exactly the same developmental stage. The expression trend of genes coding for enzymes acting on pectin, such as two GH28 (TmelPGN1 and TmelrghA) and a CE8 (Tmelpme1), has here been confirmed. In comparison with the array data, the quantitative RT-PCR data have shown the up-regulation of an additional gene putatively involved in pectin degradation, TmelPLB, coding for a protein that shows homology with a pectate lyase, in agreement with the RNAseq data. Gene coding enzymes that could act on cellulose, such as a gene coding for a GH5 (TmelCMC3), which is one of the most highly up-regulated genes in ectomycorrhizae, and two genes coding for GH12 (Tmelcel) and GH45 (TmelEG), respectively (Table 2), have also been up-regulated in truffle ectomycorrhizae. Interestingly, TmelCMC3 (GH5) was more expressed in the Hartig net compartment, thus suggesting a role during fungal penetration (Hacquard et al. 2013). In addition, it has been found that a gene coding for AA9 (TmelLPMO1) and a gene coding for a putative rhamnogalacturonan acetylesterase (TmelRgaE) are strongly up-regulated, while only a slight up-regulation has been detected from the cDNA arrays. The regulation of these genes, with an up-regulation in the ectomycorrhizal tissues, suggests their involvement when the fungus penetrates the host cells and the host walls are separated, which would allow fungal root colonization. These data are in agreement with recent data on young $T$. melanosporum ectomycorhizae that have shown an overexpression of several glycoside hydrolase genes versus the free-living mycelium, thus reflecting the ability to degrade host cell walls (Le Tacon et al. 2015). It has also been reported that two T. melanosporum transcription factor (TF) genes encoding homologs of $X \operatorname{lnR}$, an activator of cellulose/hemicellulose degrading enzymes in other fungi (Aro et al. 2005), are upregulated in T. melanosporum ectomycorrhizae (Montanini et al. 2011). It has recently been suggested that the ectomycorrhizal fungus L. bicolor regulates PCWDE expression, thus allowing a "gentle" plant cell-wall remodelling during plant colonization (Veneault-Fourrey et al. 2014). The possibility of performing these analyses at different stages of the interactions has made it possible to demonstrate that the L. bicolor CAZymes involved in hemicellulose degradation are mainly expressed during mantle formation and the root penetration of the first epidermal cells, while the CAZymes that are active on pectin and cellulose are expressed more in developed ectomycorrhizae (Veneault-Fourrey et al. 2014).

Moreover, a laser microdissection approach to dissect the response in the two fungal compartments in T. melanosporum ectomycorrhizae has made it possible to verify the concomitant induction of $T$. melanosporum genes coding for endoglucanase (GH45), an LPMO (AA9) and a cellodextrin transporter at the soil/mantle interface, thus suggesting the ability of T. melanosporum to weakly degrade cellulose (i.e., extracellular cellulolytic activity) and to assimilate the products of this activity (Hacquard et al. 2013).

\section{Hazelnut cell wall composition in the presence and absence of the ectomycorrhizal fungus}

To investigate the changes related to root colonisation by the symbiotic fungus at the biochemical level, CoMPP (Moller et al. 2007) was used to measure the intensity with which antibodies recognize specific epitopes in the cell walls of ectomycorrhizal and non-mycorrhizal root tips (Fig. 1). The CoMPP profile of the 
non-mycorrhizal roots points to a typical cell wall pattern for angiosperms (Moller et al. 2007; Fangel et al. 2012), while a decrease in all of the cell wall polymers has been revealed in the ectomycorrhizal sample, except for $(1 \rightarrow 3)$ - $\beta$-d-glucan, which can be assigned to the fungus, which also contains this polymer (Balestrini et al. 2012; Fig. 2). Although a reduction in these polymers, due to the presence of the fungal cell wall material, which could lead to a dilution of the material of plant origin, cannot be excluded, these results are in agreement with the fact that, during the colonization process, the fungus penetrates the root cells through the pectin-rich middle lamella and occupies the intercellular spaces of the root cortex (Fig. 2). The up-regulation of GH12 could explain the decrease in xyloglucans, as demonstrated by the CoMPP analysis, considering the xyloglucan specificity displayed by certain GH12 enzymes (Damásio et al. 2014). The fact that the BLASTp analysis has pointed out that Tmelcel shows homology (e value: 1e-74, identity: 56 \%) with an Aspergillus oryzae protein (XP_001820024.1; gene name, xgeA) described as a probable xyloglucan-specific endo-beta-1,4-glucanase A (EC:3.2.1.151) (Machida et al. 2005) supports this hypothesis.

Labelling experiments on C. avellana and T. melanosporum ectomycorrhizal sections has been performed to localize pectin compounds, and they have shown a different localization pattern in ectomycorrhizae for HG with a low density of methyl esterification, as recognized from the JIM5 monoclonal antibody, compared to the non-colonized roots. These results are in agreement with a previous work on hazel ectomycorrhizae, but for a different truffle species (Balestrini et al. 1996). The fact that no labelling has been seen for JIM 7 (which recognizes partially methyl-esterified HG but does not bind to un-esterified HG), although a signal for this compound is present in the CoMPP analysis, could suggest low accessibility of this polymer to the hazelnut cell wall. On the other hand, the fact that T. melanosporum cell walls are always labelled after treatment with the anti- $\beta$-1,3-glucan monoclonal antibody, as previously reported (Balestrini et al. 2012), suggests that the presence of higher signal for this component in the ectomycorrhizae in the CoMPP analysis can be correlated to its presence in the fungal cell wall.

\section{Conclusions}

CoMPP approach has been used here for the first time to detect changes in plant cell wall composition during an ectomycorrhizal interaction, thus confirming that the plant cell wall undergoes modification during the symbiotic stage. Although our data underline a difficulty in the interpretation of the results due to the presence of both fungal and plant cell-wall components, a localized degradation of HG (the most abundant plant pectin polymer) can be suggested during fungal colonization, in agreement with the growth of the colonizing fungus through the middle lamella and the fungal gene expression of genes acting on these polysaccharides. Understanding HG remodelling by specific fungal or plant enzymes, and how these changes are spatially and temporally mediated, is a central issue in addressing the fundamental role of HGtype pectins during plant growth and in plant response to environmental changes (Sénéchal et al. 2014). Considering the role of de-methylesterified HG-derived oligogalacturonides (OGs) as signalling molecules (Ferrari et al. 2013), the present findings raise the question of whether HG hydrolysis can act as a source of pectin fragments that are capable of eliciting plant responses during ectomycorrhizal symbiosis. Direct evidence of OGs acting as in vivo elicitors of the plant defence response has recently been reported by Benedetti et al. (2015), who have shown that OG release and accumulation in planta confers resistance to pathogen attack.

On the other hand, de-methylesterified HG can form the so-called "egg box" structures through binding with $\mathrm{Ca} 2+$. It has been suggested that a reduced content of egg-box structures could make other 
compounds, such as cellulose and hemicellulose, more accessible to their degrading enzymes (Lionetti et al. 2009). Other results obtained using a CBH-I complex to localize cellulose have suggested that a truffle species does not have an evident impact on this compound in the cell wall of hazel (Balestrini et al. 1996), although cell wall loosening has been suggested. The involvement of T. melanosporum enzymes acting on cellulose in cell wall loosening during fungal penetration can be hypothesized. A further step, which would probably require the development of an in vitro system, could be to evaluate the gene expression of the T. melanosporum PCWDEs at different points of time during the formation of ectomycorrhizae.

The forthcoming release of the genome sequences and annotations of additional Tuber species will allow comparison to be made of PCW degradation mechanisms in various ectomycorrhizal interactions. Finally, owing to the large variability of plant cell wall composition, it is possible that the host plant cell wall composition could influence the expression of fungal PCWDEs, and it could be interesting to investigate gene expression in several fungus/plant combinations.

\section{Author contribution statement}

FS conducted the gene expression experiments and contributed to writing the manuscript. JUF and WGTW conducted the CoMPP experiment and contributed to writing the manuscript. BE conducted the annotation and contributed to writing the manuscript. AF conducted the sample preparation for electron microscopy. PB critically revised the manuscript. FM coordinated the truffle genome project, provided the oligoarray datasets and critically revised the manuscript. RB planned the experiments, contributed to the gene annotation, conducted the microscopic observations and drafted the manuscript. All the authors read and approved the manuscript.

Acknowledgments

The Authors would like to thank Marta Vallino (Institute for Sustainable Plant Protection, Turin) for her support in the TEM observations and Annegret Kohler (INRA, Nancy) for her work on the development and management of the T. melanosporum transcriptome datasets. F. Martin's laboratory is funded and supported by the French National Research Agency through the Laboratory of Excellence ARBRE (Grant no. ANR-11-LBX-002-01) and the Plant-Microbe Interactions Project, Genomic Science Programme, of the US Department of Energy, Office of Science, Biological, and Environmental Research (Grant No. DE-AC0500OR22725).

\section{Conflict of interest}

The authors declare that they have no conflict of interest. 


\section{References}

Aro N, Pakula T, Penttila M (2005) Transcriptional regulation of plant cell wall degradation by filamentous fungi. FEMS Microbiol Rev 29:719-739

Aspeborg H, Coutinho PM, Wang Y, Brumer H, Henrissat B (2012) Evolution, substrate specificity and subfamily classification of glycoside hydrolase family 5 (GH5). BMC Evol Biol 12:186. doi:10.1186/14712148-12-186

Balestrini R, Hahn MG, Bonfante P (1996) Location of cell-wall components in ectomycorrhizae of Corylus avellana and Tuber magnatum. Protoplasma 191:55-69. doi:10.1007/BF01280825

Balestrini R, Sillo F, Kohler A, Schneider G, Faccio A, Tisserant E et al (2012) Genome-wide analysis of cell wall-related genes in Tuber melanosporum. Curr Genet 58:165-177

Balestrini R, Bonfante P (2014) Cell wall remodeling in mycorrhizal symbiosis: a way towards biotrophism. Front Plant Sci 5:237. doi:10.3389/fpls.2014.00237

Benedetti M, Pontiggia D, Raggi S, Cheng Z, Scaloni F, Ferrari S, Ausubel FM, Cervone F, De Lorenzo G (2015) Plant immunity triggered by engineered in vivo release of oligogalacturonides, damage-associated molecular patterns. Proc Natl Acad Sci USA 112:5533-5538

Cao W, Crawford DL (1993) Carbon nutrition and hydrolytic and cellololytic activities in the ectomycorrhizal fungus Pisolithus tinctorius. Can J Microbiol 39:529-535

Chang S, Pur Year J, Carney J (1993) A simple and efficient method for isolating RNA from pine trees. Plant Mol Biol Rep 11:113-116

Colpaert JV, Van Laere A (1996) A comparison of the extracellular enzyme activities of two ectomycorrhizal and a leaf-saprotrophic basidiomycete colonising beech litter. New Phytol 134:133-141

Damásio ARL, Rubio MV, Oliveira LC, Segato F, Dias BA, Citadini AP, Paixão DA, Squina FM (2014) Understanding the function of conserved variations in the catalytic loops of fungal glycoside hydrolase family 12. Biotech Bioeng 111:1494-1505. doi:10.1002/bit.25209

Duplessis S, Cuomo CA, Linc Y-C, Aertsd A, Tisserant E, Veneault-Fourrey C, Jolye DL, Hacquard S (2011) Obligate biotrophy features unraveled by the genomic analysis of rust fungi. Proc Natl Acad Sci USA 108:9166-9171. doi:10.1073/pnas.1019315108

Fangel JU, Ulvskov P, Knox JP, Mikkelsen MD, Harholt J, Popper ZA, Willats WGT (2012) Cell wall evolution and diversity. Front Plant Sci 3:152. doi:10.3389/fpls.2012.00152

Ferrari S, Savatin DV, Sicilia F, Gramegna G, Cervone F, De Lorenzo G (2013) Oligogalacturonides: plant damage-associated molecular patterns and regulators of growth and development. Front Plant Sci 4:49. doi:10.3389/fpls.2013.00049

Hacquard S, Tisserant E, Brun A, Legué V, Martin F, Kohler A (2013) Laser microdissection and microarray analysis of Tuber melanosporum ectomycorrhizas reveal functional heterogeneity between mantle and Hartig net compartments. Environ Microbiol 15:1853-1869. doi:10.1111/1462-2920.12080 
Hansen MAT, Ahl LI, Pedersen HL, Westereng B, Willats WGT, Jørgensen H, Felby C (2014) Extractability and digestibility of plant cell wall polysaccharides during hydrothermal and enzymatic degradation of wheat straw (Triticum aestivum L.). Ind Crop Prod 55:63-69

Johnsen HR, Striberny B, Olsen S, Vidal-Melgosa S, Fangel JU, Willats WGT, Rose JKC, Krause K (2015) Cell wall composition profiling of parasitic giant dodder (Cuscuta reflexa) and its hosts: a priori differences and induced changes. New Phytol 207:805-816. doi:10.1111/nph.13378

Käll L, Krogh A, Sonnhammer ELL (2004) A combined transmembrane topology and signal peptide prediction. Method J Mol Biol 338:1027-1036

Knox JP, Linstead PJ, King J, Cooper C, Roberts K (1990) Pectin esterification is spatially regulated both within cell walls and between developing tissues of root apices. Planta 181:512-521

Kohler A, Kuo A, Nagy LG, Morin E, Barry KW, Buscot F, Canbäck B, Choi C, Cichocki N, Clum A, Colpaert J et al (2015) Convergent losses of decay mechanisms and rapid turnover of symbiosis genes in mycorrhizal mutualists. Nat Genet 47:410-415

Kubicek CP, Starr TL, Glass NL (2014) Plant cell wall-degrading enzymes and their secretion in plantpathogenic fungi. Annu Rev Phytopathol 52:427-451. doi:10.1146/annurev-phyto-102313-045831

Kusuda M, Ueda M, Mihatake K, Terashita T (2008) Characterization of the carbohydrase productions of an ectomycorrhizal fungus, Tricholoma matsutake. Mycoscience 49:291-297

Le Tacon F, Zeller B, Plain C, Hossann C, Bréchet C, Martin F, Kohler A, Villerd J, Robin C (2015) Study of nitrogen and carbon transfer from soil organic matter to Tuber melanosporum mycorrhizas and ascocarps using $15 \mathrm{~N}$ and $13 \mathrm{C}$ soil labelling and whole-genome oligoarrays. Plant Soil 395:351-373

Levasseur A, Drula E, Lombard V, Coutinho PM, Henrissat B (2013) Expansion of the enzymatic repertoire of the CAZy database to integrate auxiliary redox enzymes. Biotech Biofuels 6:41. doi:10.1186/1754-6834-641

Lionetti V, Francoccia F, Ferrari S, Volpi C, Bellincampi D, Galletti R, D'Ovidio R, De Lorenzo G, Cervone F (2009) Engineering the cell wall by reducing de-methyl-esterified homogalacturonan improves saccharification of plant tissues for bioconversion. Proc Natl Acad Sci USA 107:616-621

Lodish H, Berk A, Zipursky SL et al (2000) Molecular cell biology, 4th edn. Section 22.5: The dynamic plant cell wall. WH Freeman, New York. http://www.ncbi.nlm.nih.gov/books/NBK21709/

Lombard V, Golaconda Ramulu H, Drula E, Coutinho PM, Henrissat B (2013) The carbohydrate-active enzymes database (CAZy) in 2013. Nucleic Acids Res 42:D490-D495. doi:10.1093/nar/gkt1178

Machida M, Asai K, Sano M, Tanaka T, Kumagai T, Terai G et al (2005) Genome sequencing and analysis of Aspergillus oryzae. Nature 438:1157-1161

Maijala P, Fagerstedt KV, Raudaskoski M (1991) Detection of extracellular cellololytic and proteolytic activity in ectomycorrhizal fungi and Heterobasidion annosum ( Fr) Bref. New Phytol 117:643-648

Martin F, Aerts A, Ahren D, Brun A, Danchin EGJ, Duchaussoy F et al (2008) Symbiosis insights from the genome of the mycorrhizal basidiomycete Laccaria bicolor. Nature 452:88-92. doi:10.1038/nature06556 
Martin F, Selosse M-A (2008) The Laccaria genome: a symbiont blueprint decoded. New Phytol 180:296310. doi:10.1111/j.1469-8137.2008.02613.x

Martin F, Kohler A, Murat C, Balestrini R, Coutinho PM, Jaillon O et al (2010) Périgord black truffle genome uncovers evolutionary origins and mechanisms of symbiosis. Nature 464:10331038.

doi:10.1038/nature08867

Moller IE, Sørensen I, Bernal Giraldo AJ, Blaukopf C, Lee K, Øbro J, Pettolino F, Roberts A, Mikkelsen JD, Knox JP, Bacic A, Willats WGT (2007) High-throughput mapping of cell-wall polymers within and between plants using novel microarrays. Plant J 50:1118-1128

Moller I, Marcus SE, Haeger A, Verhertbruggen Y, Verhoef R, Schols H, Ulvskov P, Mikkelsen JD, Knox JP, Willats W (2008) High-throughput screening of monoclonal antibodies against plant cell wall glycans by hierarchical clustering of their carbohydrate microarray profiles. Glycoconj J 25:37-48

Moller IE, De Fine Licht HH, Harholt J, Willats WGT, Boomsma JJ (2011) The dynamics of plant cell-wall polysaccharide decomposition in leaf-cutting ant fungus gardens. PLoS One 6:e17506.

doi:10.1371/journal.pone.0017506

Montanini B, Levati E, Bolchi A, Kohler A, Morin E, Tisserant E, Martin F, Ottonello S (2011) Genome-wide search and functional identification of transcription factors in the mycorrhizal fungus Tuber melanosporum. New Phytol 189:736-750. doi:10.1111/j.1469-8137.2010.03525.x

Nagendran S, Hallen-Adams HE, Paper JM, Aslama N, Walton JD (2009) Reduced genomic potential for secreted plant cell-wall degrading enzymes in the ectomycorrhizal fungus Amanita bisporigera, based on the secretome of Trichoderma reesei. Fungal Genet Biol 46:427-435. doi:10.1016/j.fgb.2009.02.001

Pedersen HL, Fangel JU, McCleary B, Ruzanski C, GroRydahI MG, Ralet M-C, Farkas V, Schantz L, Marcus SE, Andersen MCF, Field R, Ohlin M, Knox JP, Clausen MH, Willats WGT (2012) Versatile high resolution oligosaccharide microarrays for plant glycobiology and cell wall research. J Biol Chem 287:39429-39438

Pfaffl MW, Horgan GW, Dempfle L (2002) Relative expression software tool (REST) for group-wise comparison and statistical analysis of relative expression results in Real-Time PCR. Nucleic Acids Res 30:E36

Sénéchal F, Wattier C, Rustérucci C, Pelloux J (2014) Homogalacturonan-modifying enzymes: structure, expression, and roles in plants. J Exp Bot 65:5125-5160. doi:10.1093/jxb/eru272

Sillo F, Gissi C, Chignoli D, Ragni E, Popolo L, Balestrini R (2013) Expression and phylogenetic analyses of the Gel/Gas proteins of Tuber melanosporum provide insights into the function and evolution of glucan remodeling enzymes in fungi. Fungal Gen Biol 53:10-21

Sillo F, Zampieri E, Giordano L, Lione G, Colpaert JV, Balestrini R, Gonthier P (2015) Identification of genes differentially expressed during the interaction between the plant symbiont Suillus luteus and two plant pathogenic allopatric Heterobasidion species. Mycol Progress 14:106

Sørensen I, Willats WG (2011) Screening and characterization of plant cell walls using carbohydrate microarrays. Methods Mol Biol 715:115-121. doi:10.1007/978-1-61779-008-9_8 
Stam MR, Danchin EGJ, Rancurel C, Coutinho PM, Henrissat B (2006) Dividing the large glycoside hydrolase family 13 into subfamilies: towards improved functional annotations of alpha-amylase-related proteins. Protein Eng Des Sel 19:555-562

Tamura K, Stecher G, Peterson D, Filipski A, Kumar S (2013) MEGA6: Molecular Evolutionary Genetics Analysis Version 6.0. Biol Evol 30:2725-2729

Tisserant E, Da Silva C, Kohler A, Morin E, Wincker P, Martin F (2011) Deep RNA sequencing improved the structural annotation of the Tuber melanosporum transcriptome. New Phytol 189:883-891

Veneault-Fourrey C, Commun C, Kohler A, Morin E, Balestrini R, Plett J, Danchin E, Coutinho P, Wiebenga A, de Vries RP, Henrissat B, Martin F (2014) Genomic and transcriptomic analysis of Laccaria bicolor CAZome reveals insights into polysaccharides remodelling during symbiosis establishment. Fungal Biol Gen 72:168181

Verhertbruggen Y, Marcus SE, Haeger A, Ordaz-Ortiz JJ, Knox JP (2009) An extended set of monoclonal antibodies to pectic homogalacturonan. Carbohydr Res 344:1858-1862

Willats WGT, Knox JP, Mikkelsen JD (2006) Pectin: new insights into an old polymer are starting to gel. Trends Food Sci Tech 17:97-104 